\title{
OBSERVATIONS OF PLANETARY NONTHERMAL RADIATION OBSERVATIONS OF PLANETARY NONTHERMAL RADIATION
}

\author{
HARLAN J. SMITH AND J. N. DOUGLAS \\ Yale University, New Haven, Connecticut, U.S.A.
}

Observations at Yale of planetary nonthermal noise were first made in 1957 from March to June at $21.1 \mathrm{Mc} / \mathrm{s}$ by a single close-spaced phase-switching interferometer with Yagi elements. To be accepted as possibly planetary, noise events had to be unidentifiable as terrestrial; they had to fit the interferometer pattern; and they had to occur when the planet was in the Yagi beams. Thirteen events satisfied these criteria for Jupiter (Fig. la), giving the rotation histogram Fig. $2 a$ when plotted according to the System III period of Carr et al. [1]. The pattern is quite similar to that obtained for the immediately preceding months by the Florida group (Fig. 2b).

The same criteria yielded fifteen events (Fig. 1b) of similar appearance, which appeared possibly to fit Saturn; certainly they did not apply to Jupiter. A rotation period of 10.37 hours, well within the optical range, would concentrate all but one of the events toward a single hemisphere of Saturn. While these records are suggestive, they do not suffice to establish Saturn as a source, since the interferometer pattern was too coarse and interference levels were too high for certain discrimination.

Records were taken in 1958 from April through July with equipment capable of much higher discrimination. Three 23.0-Mc/s units (a single antenna, a 360 -foot interferometer, and a 960 -foot interferometer) were located at the

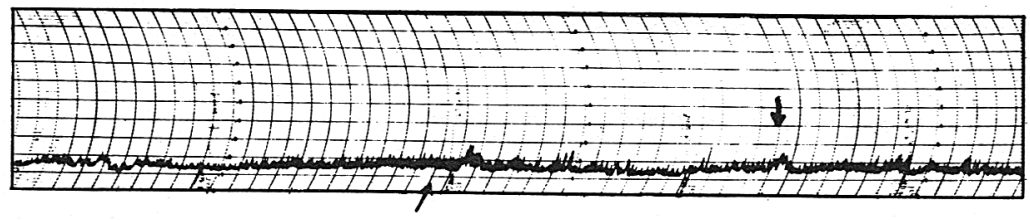

a

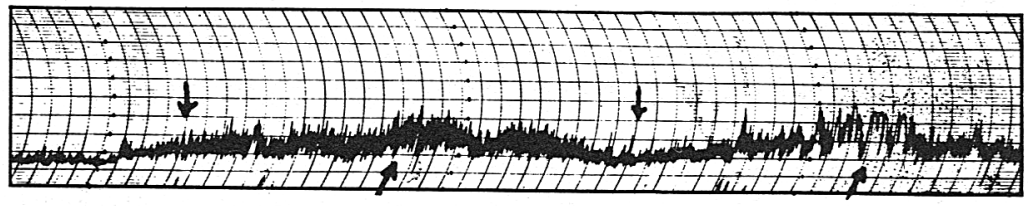

b

Fig. 1. Sample 1957 records. Arrows snow computed interterometer maxima and nulls. (a) April $12,05^{\mathrm{h}} 27^{\mathrm{m}}$ to $07^{\mathrm{h}} 36^{\mathrm{m}}$ U.T., containing probable Jupiter noise; (b) May 14 , $03^{\mathrm{h}} 22^{\mathrm{m}}$ to $05^{\mathrm{h}} 35^{\mathrm{m}}$ U.T., noise fitting Saturn's position in pattern. 
vertices of a right triangle having sides 11 and 35 miles; a second 960 -foot interferometer was operated at the same site as the other but on $22.2 \mathrm{Mc} / \mathrm{s}$. The higher frequency range of this year was chosen in the hope of avoiding some interference, particularly in spring and summer, while remaining within the band where Jupiter storms are readily detected. Eight Jupiter events (Fig. 3a) were found, all of them rather weak, with maximum powers of the order of $10^{-21}$ watts $\mathrm{m}^{-2}(\mathrm{c} / \mathrm{s})^{-1}$; the rotation histogram Fig. $2 c$ suggests a phase shift from 1957 in the sense that the Florida System III is several seconds too short.

Only two events appeared to fit Saturn: in one, the signal and pattern discrimination were weak; while the other (Fig. $3 b$ ) was picked up only on 22.2 $\mathrm{Mc} / \mathrm{s}$. Again the data fall short of proof.

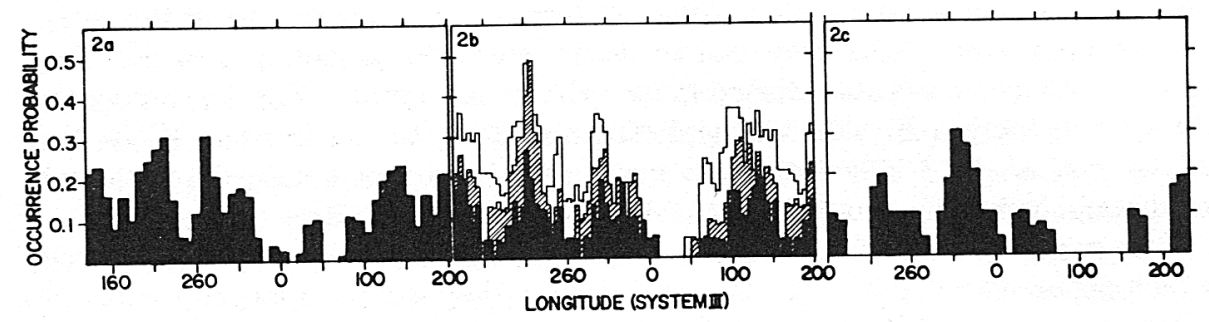

FIG. 2. Occurrence probability histograms. (a) Yale $21.1 \mathrm{Mc} / \mathrm{s}, 1957$ March-May; (b) Florida $18 \mathrm{Mc} / \mathrm{s}, 1957$ January-March; (c) Yale $23.0 \mathrm{Mc} / \mathrm{s}, 1958$ April-June (unit of occurrence probability 0.01 ).
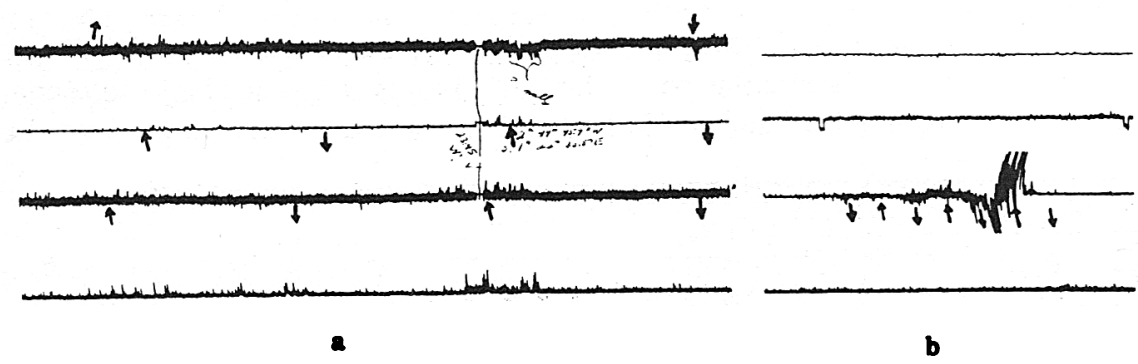

Frg. 3. Sample 1958 4-channel records. From top to bottom: 360 -foot $(23.0 \mathrm{Mc} / \mathrm{s})$, 960 -foot $(23.0 \mathrm{Mc} / \mathrm{s}), 960$-foot $(22.2 \mathrm{Mc} / \mathrm{s})$, total power $(23.0 \mathrm{Mc} / \mathrm{s})$. (a) May 26, $04^{\mathrm{h}} 5^{\mathrm{m}}$ to $05^{\mathrm{h}} 26^{\mathrm{m}}$ U.T., weak Jupiter storm; (b) June $16,05^{\mathrm{h}} \mathrm{7}^{\mathrm{m}}$ to $06^{\mathrm{h}} 58^{\mathrm{m}} \mathrm{U}$.T., showing 45-minute event fitting $22.2 \mathrm{Mc} / \mathrm{s}$ computed phase reversals for Saturn.

During positively identified Jupiter storms, pulse elements having durations of the order of one second showed about 80 per cent correlation between the separated stations, and between the $22.2-$ and $23.0-\mathrm{Mc} / \mathrm{s}$ channels at the same station; for corresponding counts made when the storm was not in evidence the correlations dropped to about 20 per cent.

We conclude that Saturn remains a tantalizing, though still doubtful, possible 
NO. 8

source; that Jupiter in the last two years has shown burst occurrence probabilities roughly in the ratio $1: 0.8: 0.1$ for frequencies 18,21 , and $23 \mathrm{Mc} / \mathrm{s}$; and that there is good correlation between the longer pulse elements of storms over $0.8-\mathrm{Mc} / \mathrm{s}$ frequency separation around $23 \mathrm{Mc} / \mathrm{s}$ and between sites separated by tens of miles.

\section{REFERENCE}

[1] Carr, T. D., Smith, A. G., Pepple, R., and Barrow, C. H. Ap. J. 127, 274, 1958. 